\title{
Local control of giant cell tumors of the long bone after aggressive curettage with and without bone cement
}

Zhen-hua Gao ${ }^{1 \dagger}$, Jun-qiang Yin ${ }^{2 \dagger}$, Xian-biao Xie ${ }^{2+}$, Chang-ye Zou ${ }^{2}$, Gang Huang ${ }^{2}$, Jin wang ${ }^{2}$ and Jing-nan Shen ${ }^{2^{*}}$

\begin{abstract}
Background: Aggressive curettage has been well established for the treatment of giant cell tumors (GCTs) of the bone. The purpose of this study was to review our experience and evaluate the role of different implant materials in patients with GCTs of the extremities after aggressive curettage.

Methods: A total of 119 patients with GCTs of the long bone were treated at the First Affiliated Hospital of Sun Yat-Sen University between 2004 and 2009. We excluded patients presenting metastases, recurrent tumors, and soft tissue involvement and those with Jaffe pathological grade III. The remaining 65 patients were treated with aggressive curettage using a bone graft or bone cement to fill the cavity. The recurrence rates and functional scores associated with the different fillings were analyzed.

Results: Aggressive curettage and bone grafting was performed in 34 cases (52.3\%), and aggressive curettage with bone cement was performed in 31 cases (47.7\%). The overall recurrence rate after the aggressive intralesional procedures was $35.3 \%$ with bone grafting and $12.9 \%$ when bone cement was used as an adjuvant filling. The recurrence rate following aggressive curettage and bone grafting was higher than that following aggressive curettage with cement $(p=0.038)$. The Musculoskeletal Tumor Society (MSTS) score for bone graft patients was $91.1 \%$, which was significantly lower than that for patients treated with bone cement (94.7\%).

Conclusions: The use of bone cement was associated with a significantly lower recurrence rate than bone grafting following aggressive intralesional curettage to treat benign giant cell tumors of the long bone. Better MSTS functional results were also observed in the bone cement group compared to the bone graft group.
\end{abstract}

Keywords: Giant cell tumor of the long bone, Bone graft, Bone cement, Aggressive curettage, Local recurrence

\section{Background}

Giant cell tumors (GCTs) are primary benign bone tumors with invasive and potentially malignant characteristics [1-3]. Intralesional curettage is the main surgical treatment option [4,5]. After curettage, filling the cavity with bone grafts or cement is commonly performed to provide structural support and prevent collapse [6]. Previous studies have shown that using bone cement as a filler can significantly reduce the relapse rate after curettage [7-9]. In recent years, with the application of aggressive curettage technology, which is characterized by

\footnotetext{
* Correspondence: shenjingnan@126.com

${ }^{\dagger}$ Equal contributors

${ }^{2}$ Department of Orthopaedics, First Affiliated Hospital of Sun Yat-Sen University, 58\# zhongshan 2 road, Guangzhou 510080, P.R. China

Full list of author information is available at the end of the article
}

the use of a high-speed burr and other auxiliary methods, the giant cell tumor recurrence rate has been well controlled, and there is a new argument regarding the best type of implant material to use after aggressive curettage [10-12]. It is well known that the GCT outcome may differ according to many factors, including the presence of metastatic disease at diagnosis, pathological fracture, soft tissue involvement, and anatomical site $[7,13,14]$. Therefore, it is very difficult to make a reliable assessment regarding the role of different implant materials, and it is important to assess the role of different implant materials in a group of patients with the same or similar clinical conditions.

The aim of this study was to retrospectively review our experience with GCTs in patients with similar clinical 
conditions by assessing the contribution of different implant materials to local control and functional results.

\section{Methods}

\section{Patient selection}

A total of 119 patients with GCTs of the long bone were treated at the First Affiliated Hospital of Sun Yat-Sen University between 2004 and 2009. The patient selection criteria for this retrospective study were as follows: no previous treatment, no metastases at diagnosis, no pathological fracture, no soft tissue involvement, Jaffe pathological grade I or II [15], and underwent aggressive curettage. Sixty-four cases were excluded, and the remaining 65 cases constituted the group included in the current study. Then, the patients were divided into two groups according to the different local implant materials: Group 1, 34 patients who underwent aggressive curettage and bone grafting (allograft and/or autograft); and Group 2, who underwent aggressive curettage with bone cement fillings. This study was approved by First Affiliated Hospital of Sun Yat-Sen University ethics committee to access patient data for clinical research.

\section{Preoperative imaging and pathological examination and evaluation}

The imaging procedures included preoperative anteroposterior and lateral X-ray examinations, MRI of the ipsilateral long bone using $1.5 \mathrm{~T}$ and $3.0 \mathrm{~T}$ superconductive MR units (Magnetom Vision, Magnetom Trio Tim, Siemens, Medical System, Erlangen, Germany), and a preoperative anteroposterior chest $\mathrm{X}$-ray examination. Axial and coronal or sagittal T1WI (TR 420$600 \mathrm{~ms}$ and TE $12-20 \mathrm{~ms}$ ) and T2WI (TR 2500-4500 ms and TE $80-120 \mathrm{~ms}$ ) sequences were used. The scanning slice thickness was $4 \mathrm{~mm}$ with a $1 \mathrm{~mm}$ interval. Two experienced radiologists independently observed and recorded the X-ray and MRI findings of the giant cell tumors and agreed upon a diagnosis. The imaging findings included the integrity of the bone shell, with or without a soft tissue mass, and with or without lung metastases on the chest X-ray film. Histological sections and records were available in all cases and were reviewed and confirmed by two experienced pathologists.

\section{Tumor volume measurement}

The anteroposterior and mediolateral maximum diameters of the tumors were measured on preoperative axial MR images. The longitudinal maximum diameters of tumors were measured on preoperative coronal or sagittal MR images in the long bones. The tumor volume was calculated using the formula as follows: Tumor volume $=\Pi$ / 6 (anteroposterior maximum diameter $\times$ mediolateral maximum diameter $\times$ longitudinal maximum diameter), according to the methods used by Bieling P et al. [16].

\section{Treatment protocol}

Local treatment consisted of aggressive curettage (highspeed burring, alcohol and iodine tincture as adjuvant) and bone grafting (Figure 1B) or aggressive curettage with cement (Figure 1D). The type of local treatment was chosen for each patient based on careful consideration of data and after a discussion with radiotherapists, surgeons, and medical oncologists. The choice of local treatment was tailored to each patient's characteristics: age; tumor site, size, and grade; and expected level of function.

\section{Postoperative follow-up}

All patients were followed up to review clinical functional results and perform an X-ray examination at 3 months, 6 months, 9 months, and 12 months after the clinical operation and continued to be followed up every

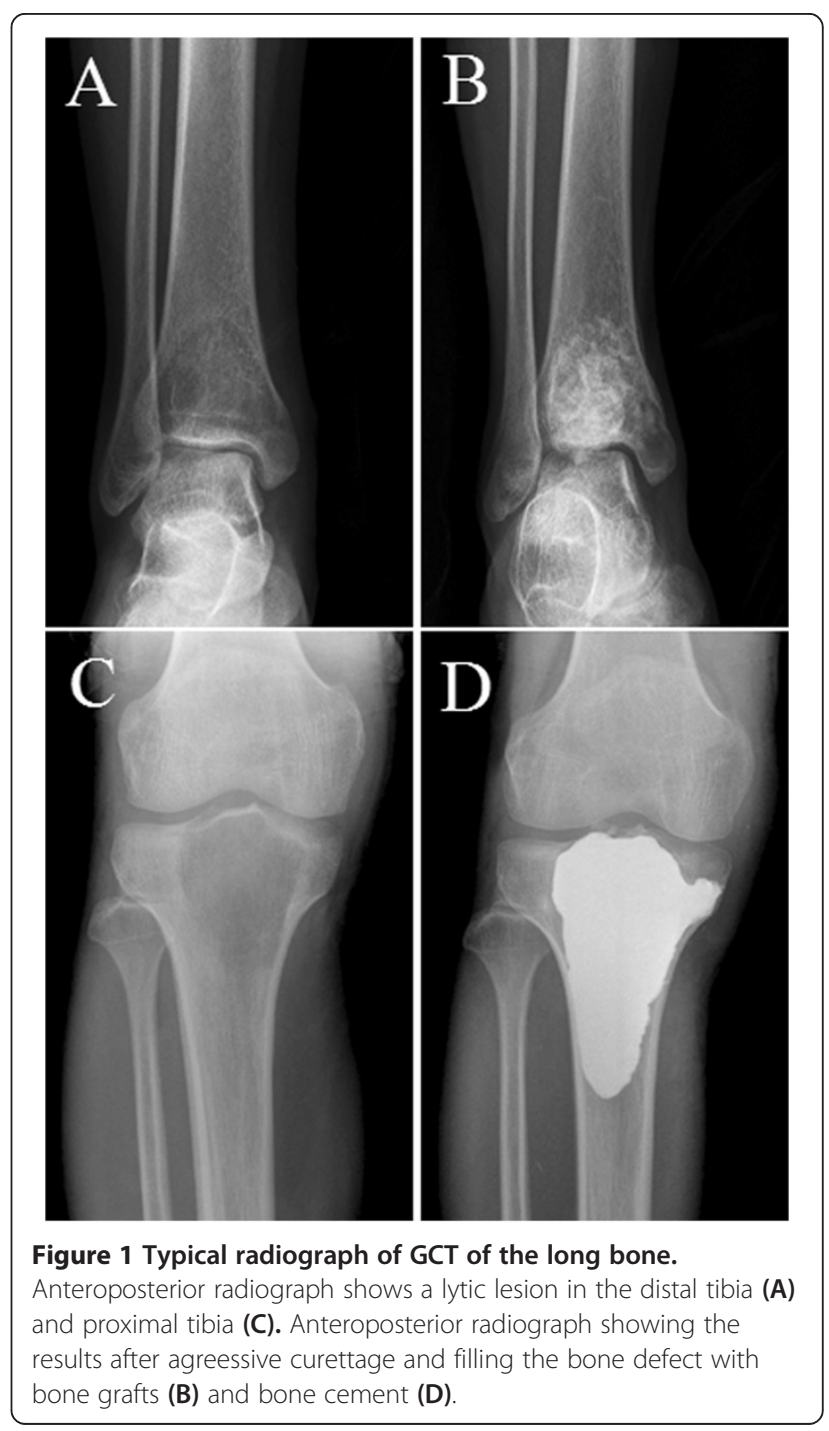


6 months thereafter. The Musculoskeletal Tumor Society score, developed by Enneking, was used to assess functional results [17]. Local tumor recurrence was determined by X-ray, and MRI was chosen if the clinical manifestations or X-ray findings could not confirm local tumor recurrence. All recurrent tumors were confirmed by a second surgical pathology. The end of follow-up for this study was the time of tumor recurrence.

\section{Statistical analysis}

The chi-square test was used to evaluate the statistical association between two variables. The Kaplan-Meier and log-rank methods were used to draw and evaluate the significance of event-free survival curves. One-way ANOVA was used to highlight different functional results between the different implant materials. A difference was considered statistically significant when the P-value was less than 0.05 . Statistical analyses were performed using the Statistical Package for the Social Sciences (SPSS), version 19.0 (SPSS Inc., Chicago, USA).

\section{Results}

\section{Clinical appearance}

Of the 65 patients in our study, 33 were male and 32 were female, with a mean age of 31.8 years (range: 1865 years). The tumor site was the proximal femur in 4 cases, the distal femur in 28 cases, the proximal tibia in 27 cases, the distal radius in 5 cases, and the distal tibia in 1 case. The tumor volume ranged from 4 to $310 \mathrm{ml}$, with an average of $68 \mathrm{ml}$. The Jaffe pathological grades of the tumors were as follows: I, 14 cases; II, 51 cases. The mean follow-up time was 38.8 months, ranging from 6 to 84 months. At the scheduled follow-up visits, 49 patients (75.4\%) had no evidence of disease, and 16 (24.6\%) demonstrated local recurrence. The interval between surgery and local recurrence for the 16 patients treated at our hospital ranged from 6 months to 5 years (average, 19.8 months) postoperatively. Thirteen patients (81.3\%) had a local recurrence within 2 years after surgery (Figure 2 ). Only 3 patients $(18.7 \%)$ had a recurrence after more than 2 years.

\section{Event-free survival analysis}

Univariate analyses, as shown in Table 1, were first performed for all 65 patients. Sex, age, tumor site, tumor volume, and pathological grade were not significant. The rate of 3-year EFS was significantly lower for local treatment with bone grafting compared to cement ( $64.7 \%$ vs. $87 \%, P=0.038)$. In contrast to other studies, proximal femur cases had the best prognosis (100\%, 3-year EFS), and the distal femur location had the worst $(71.4 \%$, 3year EFS). Even more interestingly, patients with a tumor volume less than $50 \mathrm{ml}$ had a worse 3-year EFS (71.0\%) than those with larger tumors (79.4\%); this difference was not significant $(P=0.433)$. Although patients with Jaffe pathological grade I had a higher 3-year EFS than those of grade II, this difference was not significant $(P=0.089)$. The Kaplan-Meier and log-rank life table analyses also confirmed that local treatment with cement was significantly associated with a higher probability of better events and a better outcome (Figure 3).

\section{Comparison of different adjuvant therapies}

To further investigate the effects of different adjuvant therapies for local control, we compared the clinical features of different local treatments (Table 2). Of the 34 patients in the progressive curettage and bone grafting group (Group 1), 17 were male and 17 were female. The age ranged from 18 to 49 years old, with an average of 30.7 years. The tumor site was the proximal femur in 4

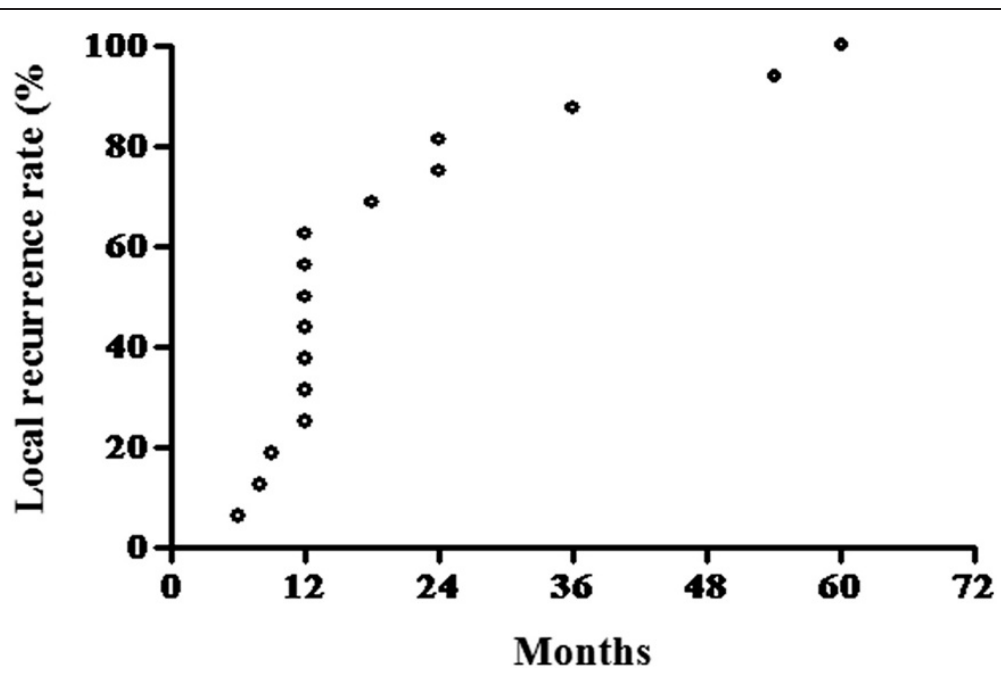

Figure 2 The interval between surgery and local recurrence for the 16 recurrene patients treated at our hospital. 
Table 1 Analysis of clinic factors predicting 3-year event free survival (EFS) of 65 patients

\begin{tabular}{|c|c|c|c|c|}
\hline Variable & $\begin{array}{c}\text { No.of } \\
\text { cases (65) }\end{array}$ & $\begin{array}{c}\text { EFS } \\
\text { patients (49) }\end{array}$ & $\begin{array}{l}\% \text { EFS } \\
(75.4)\end{array}$ & P-value \\
\hline Sex & & & & 0.944 \\
\hline male & 33 & 25 & 75.8 & \\
\hline female & 32 & 24 & 75.0 & \\
\hline Age(Yrs.) & & & & 0.616 \\
\hline$\leq 30$ & 33 & 24 & 72.7 & \\
\hline$>30$ & 32 & 25 & 78.1 & \\
\hline Site & & & & 0.75 \\
\hline Proximal femur & 4 & 4 & 100.0 & \\
\hline Distal femur & 28 & 20 & 71.4 & \\
\hline Proximal tibia & 27 & 20 & 74.1 & \\
\hline Distal radius & 5 & 4 & 80.0 & \\
\hline Distal tibia & 1 & 1 & 100.0 & \\
\hline Tumor volume(ml) & & & & 0.433 \\
\hline$\leq 50$ & 31 & 22 & 71.0 & \\
\hline$>50$ & 34 & 27 & 79.4 & \\
\hline Grade & & & & 0.089 \\
\hline । & 14 & 13 & 92.9 & \\
\hline$\|$ & 51 & 36 & 70.6 & \\
\hline Local treatment & & & & 0.038 \\
\hline Bone graft & 34 & 22 & 64.7 & \\
\hline Cement & 31 & 27 & 87.1 & \\
\hline
\end{tabular}

cases, the distal femur in 11 cases, the proximal tibia in 13 cases, the distal radius in 5 cases, and the distal tibia in 1 case. The tumor volume ranged from 4 to $185 \mathrm{ml}$, with an average of $42 \mathrm{ml}$. The Jaffe pathological grades were as follows: I, 10 cases; II, 24 cases. The follow-up time was between 6 and 84 months, with an average of 37.7 months. Local tumor recurrence was evident in 12 patients in this group (35.3\%). The tumor was detected from 6 to 60 months (mean 17.9 months) after local treatment.

Of the 31 patients in the progressive curettage and cement group (Group 2), 16 were male and 15 were female. The age ranged from 19 to 65 years old, with an average of 33.1 years. The tumor site was the proximal femur in 1 case, the distal femur in 16 cases, and the proximal tibia in 14 cases. The tumor volume ranged from 28 to $310 \mathrm{ml}$, with an average of $96 \mathrm{ml}$. The Jaffe pathological grades were as follows: I, 4 cases; II, 27 cases. The follow-up period ranged from 12 to 72 months, with an average of 46.5 months. In this group, local recurrence was detected in four patients $(12.9 \%)$ at 12 to 54 months (mean 20.4 months) after surgery.

Regarding the patient clinical features of the two groups, one significant difference was tumor volume (Table 2). In the bone graft group, tumor volume was significantly smaller compared to the cement group $(\mathrm{P}<$ 0.001). The local recurrence rate of the bone graft group was also higher compared to the cement group, and this difference reached statistical significance $(\mathrm{P}<0.05)$.

Different MRI manifestation in the two groups

Six patients have been underwent MRI examination during follow up with an average of 9.8 months (6-14 months),

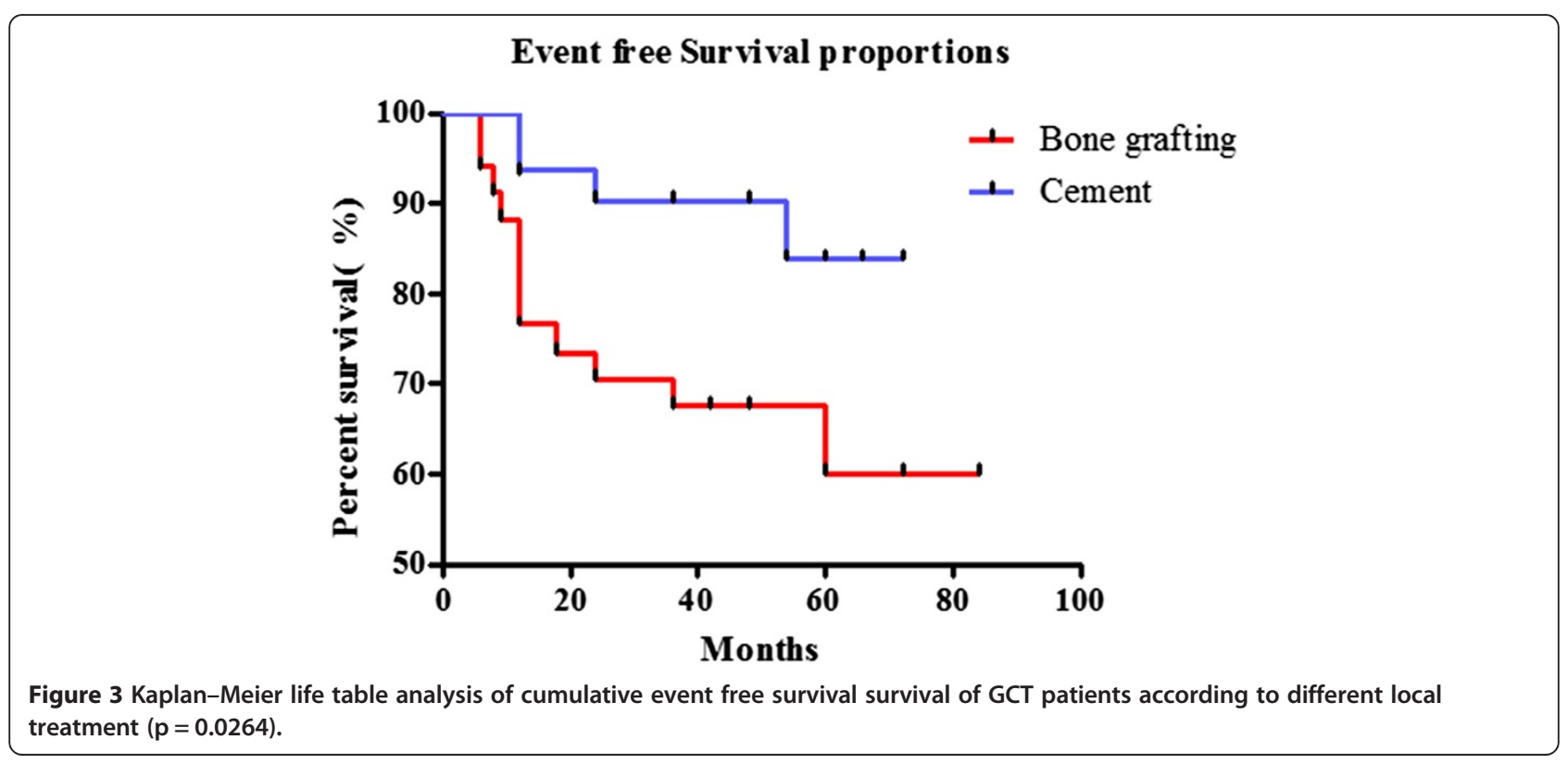


Table 2 Comparison of clinic data of 65 patients with GCT according to different treatment group 1 vs group 2

\begin{tabular}{|c|c|c|c|}
\hline Patient data & Group 1 & Group 2 & P-value \\
\hline No.of patients & 34 & 31 & \\
\hline Sex & & & 0.897 \\
\hline Male & 17 & 16 & \\
\hline Female & 17 & 15 & \\
\hline Age (Yrs.) & & & 0.716 \\
\hline$\leq 30$ & 18 & 15 & \\
\hline$>30$ & 16 & 16 & \\
\hline Site & & & 0.358 \\
\hline Proximal femur & 4 & 0 & \\
\hline Distal femur & 11 & 17 & \\
\hline Proximal tibia & 13 & 14 & \\
\hline Distal radius & 5 & 0 & \\
\hline Distal tibia & 1 & 0 & \\
\hline Tumor volume(ml) & & & $<0.001$ \\
\hline$\leq 50$ & 26 & 5 & \\
\hline$>50$ & 8 & 26 & \\
\hline Grade & & & 0.109 \\
\hline । & 10 & 4 & \\
\hline$\|$ & 24 & 27 & \\
\hline Local recurrence & & & 0.038 \\
\hline Yes & 12 & 4 & \\
\hline No & 22 & 27 & \\
\hline
\end{tabular}

4 in the bone graft group and 2 in the cement group. An abnormal banded signal around the area filled with bone cement was found in the two cement group cases (Figure 4A,B). Howerer, there was no similar MRI findings in the bone grafting group (Figure 4C,D).

\section{Comparison of the MSTS functional scores in the two groups}

Better functional results were observed following treatment with cement compared to bone grafting. The mean score in the cement group was 94.7 (SD 5.4), whereas it was 91.1 (SD 7.5) after bone grafting. One-way ANOVA showed a significant difference between the type of adjuvant therapy and functional, outcome $(\mathrm{P}=0.011)$.

\section{Discussion}

GCTs of the bone are aggressive and potentially malignant primary bone tumors that often occur at the end of the long bone in adults aged $20 \sim 40$ years old $[18,19]$. These tumors are primarily composed of stromal cells and multinucleated giant cells; the stromal cells are the main tumor cell component in GCTs of the bone $[20,21]$. According to microscopic morphological findings, Jaffe created a pathological classification system for
GCTs, including grades I-III. In the new bone tumor classification released by the WHO in 2002, GCTs of the bone were divided into GCTs and malignant GCTs. The former are equivalent to grades I $\sim$ II, and the latter is equivalent to grade III.

Surgical treatment options include intralesional excision or segmental resection [7,14]. Curettage has a higher recurrence rate $[22,23]$, but it preserves adjacent joint function. The ideal treatment of GCTs consists of excising the tumor and sparing the joint. Therefore, many scholars believe that GCTs should be treated using curettage [24,25]. To avoid local recurrence, aggressive curettage has been widely used and has achieved good clinical results $[12,14]$. The recommended aggressive curettage technique involves opening the bone through a large cortical window that allows visualization of the entire tumor cavity. After curettage is achieved, the cavity is deepened with the use of high-speed burrs [14,26]. Various adjuvant therapies (including phenol and liquid nitrogen) may be employed in conjunction with curettage, and these most likely reduce the risk of recurrence compared with curettage alone $[19,25]$.

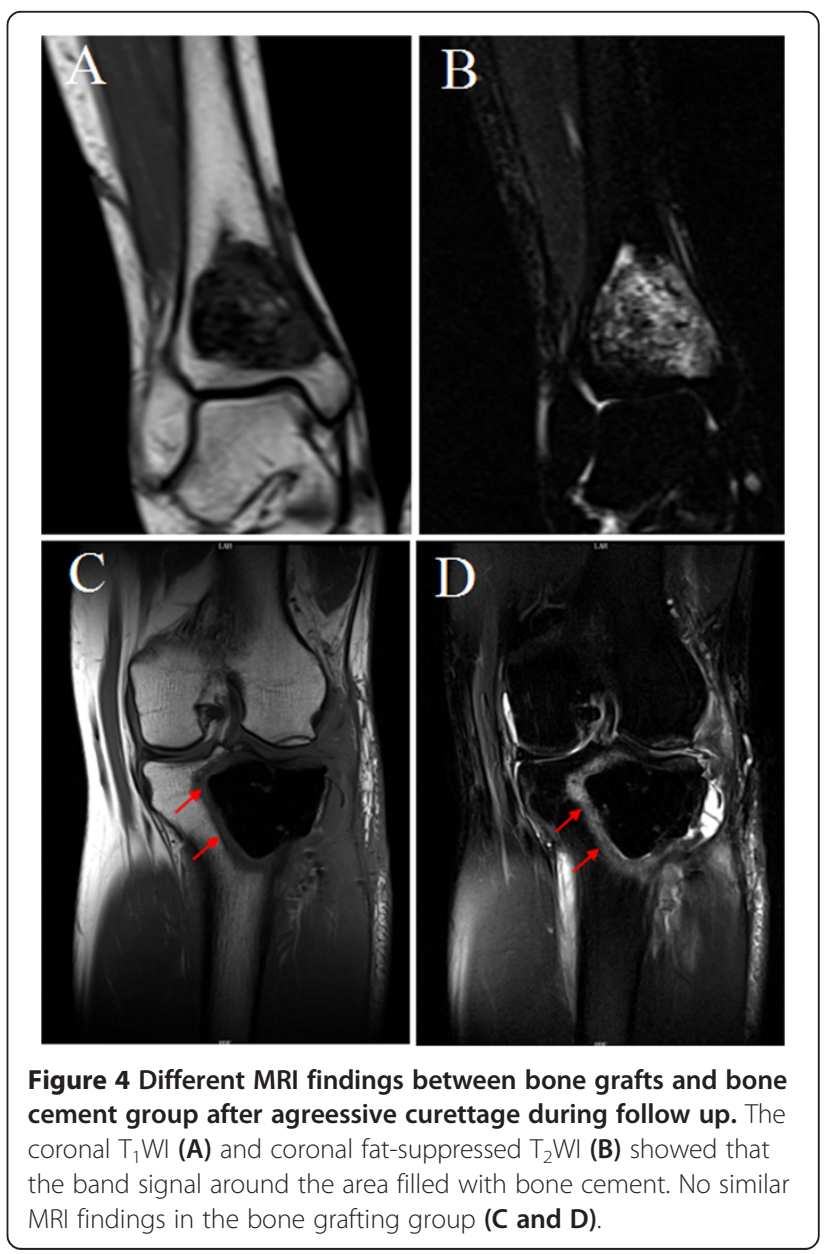


After tumor evacuation, the cavity can be filled with cement or bone grafting [10]. The literature is divided as to whether the bone defect should be filled using bone grafts or cement. In the Scandinavian Sarcoma Group multicenter study by Kivioja et al. [8], which involved 294 patients, filling the cavity with cement was shown to be a prognostic factor. The recurrence rate was $20 \%$ for filling with cement and 56\% for intralesional surgery without cementation $(\mathrm{p}=0.001)$. Becker WT et al. [13] has also reported that the use of bone cement as an adjuvant significantly reduces the recurrence rate following intralesional treatment of benign giant cell tumors, and it appears to be the therapy of choice for primary as well as recurrent giant cell tumors of the bone. By contrast, in the Canadian multicenter study by Turcotte et al. [11], which involved 186 patients, the adjuvant method or filling material was not significantly associated with the risk of recurrence. By retrospectively reviewing the records and images of 621 extremity GCT patients between 1989 and 2009, Niu X et al. [12] also concluded that bone grafting did not affect local tumor control after aggressive curettage and that the local recurrence rate was $11.1 \%$ if bone grafting was used. Similar results were also reported by Errani $C$ et al. [14]; although cement decreased local recurrence, the influence of adjuvants was not statistically significant.

Many factors might influence the treatment outcome of GCTs [7,13,27], and none of these studies were randomized. Therefore, the evaluation of prognostic factors and the assessment of different local treatments may be affected by selection bias. Errani C [14] stated that no prospective randomized studies have shown the effects of different methods of filling the cavity. However, the main shortcoming of these retrospective reviews is the analysis of patients over a long time period, over which many changes in imaging studies, pathological examinations, and surgical treatments occurred, altering the diagnostic approach and treatment of patients with GCTs.

To avoid this problem, we used detailed patient selection criteria for this retrospective study performed for 2004-2009, including patients who underwent aggressive curettage. The operative procedure was also limited to three senior surgeons in our department. Our retrospective review attempted to identify prognostic factors useful to evaluate the risk level for each patient and possibly determine the strategies of GCT treatment.

After the univariate analysis, no significant statistical effect on the local recurrence rate was observed for gender, age, tumor volume, or Jaffe grade. Only the type of implant materials emerged as a significant factor. Bone cement was shown to be more effective at treating GCT compared with bone grafting. The Kaplan-Meier and logrank life table analysis also confirmed that local cement treatment was significantly associated with a higher probability of better events and a better outcome. Regarding our patients' clinical features, the only significant difference between the two groups was tumor volume (Table 2); in the bone grafting group, tumor volume was significantly smaller compared to the cement group $(P<0.001)$. Patients with small primary tumors might have a better prognosis and be more likely to be cured by bone grafting. However, bone grafting patients with smaller tumors relapsed more often compared to the cement group, which further suggests that bone cement is an effective adjuvant to treat GCT of the long bone, even for larger tumors.

Similar to marginal excision, it is difficult to completely remove residual tumor cells in the inner wall of the cavity using aggressive curettage, and there is still the possibility of relapse. Compared with bone grafting, bone cement can be combined with firmly scraping the edges of the residual cavity. When bone cement solidifies, it releases polymerizing heat reaching $80-90^{\circ} \mathrm{C}$, which has a high-temperature inactivation effect on the residual cavity of the tumor [28,29]. These factors are most likely the main reasons for the lower recurrence rate with bone cement fillings compared to bone grafting. We also found an abnormal banded signal around the area filled with bone cement by MRI (Figure 4A,B), which could reflect damage to the surrounding bone marrow due to the high-temperature effect. Howerer, there was no similar MRI findings in the bone grafting group (Figure 4C,D).

In most cases, the tumor recurred during the first two years $(81.3 \%)$ after surgery in our series, which is consistent with other studies $[1,14]$, but the longest recurrence required 5 years to develop. Therefore, we suggest that patients should be evaluated through at least the 5 th year after the final surgery. The data also showed that the GCT recurrence rates were $66.7 \%$ for bone grafting and $50 \%$ for bone cement one year after surgery, while they were $83.3 \%$ for bone grafting and $75 \%$ for bone cement in the first two years. These data indicate that the different implants and different postoperative times may lead to differences in the tumor recurrence rate following aggressive curettage of giant cell tumors of the long bone.

In other studies, tumor location significantly affected prognosis. Due to the difficulty associated with treatment, the distal radius and proximal femur are associated with a higher rate of local recurrence [14,30]. However, there was no statistical correlation between tumor location and prognosis in our series.

For giant cell tumors of the long bones, the theoretical advantages of bone grafting, if the tumor does not relapse, include the ability of autologous or allograft bone to achieve bone healing, satisfactory recovery and no revisions. In contrast to our expectation, better functional 
results were observed in the cement group compared to the bone grafting group $(\mathrm{P}=0.011)$ in our series. This discrepancy may due to the early weight-bearing activities of cement group patients and the short follow-up period during which bone cement-related complications, such as osteoporosis, were observed less often.

The limitations of our study include the retrospective analysis and the lack of random assignment of the type implant material used due to the tailored choice made according to each patient's requirements.

\section{Conclusion}

In conclusion, we showed that the use of bone cement in a group of patients with GCTs of the long bone resulted in a lower local recurrence rate when compared to bone graft patients following aggressive intralesional curettage treatment. Better MSTS functional results were also observed after bone cement compared to the bone graft group. A prospective randomized study evaluating the effects of different methods of filling the cavity should be performed in the near future.

\section{Abbreviations \\ GCTs: Giant cell tumors; MRI: Magnetic resonance imaging; SD: Standard deviation; MSTS: Musculoskeletal Tumor Society; WHO: World Health Organization.}

\section{Competing interests}

The authors declare that they have no competing interests.

\section{Authors' contributions}

ZHG and JQY accountable for the integrity and analysis of the data, and the writing of the manuscript. CYZ and XBX accountable for the collected and analyzed data. JW analyzed data and gave radiologic support. GH analyzed data and supported genetic analysis. JNS planned the study, collected data and wrote the manuscript. All authors read and approved the final manuscript.

\section{Acknowledgements}

The authors would like to thank all participating patients, the study nurses, co-investigators, and colleagues who made this trial possible.

\section{Funding}

This work was supported by grants from National Natural Science Foundation of China (No. 30973504, No. 81102040); Sun Yat-Sen University Clinical Research 5010 Program.

\section{Author details}

'Department of Radiology, First Affiliated Hospital of Sun Yat-Sen University, Guangzhou 510080, China. ²Department of Orthopaedics, First Affiliated Hospital of Sun Yat-Sen University, 58\# zhongshan 2 road, Guangzhou 510080, P.R. China.

Received: 19 March 2014 Accepted: 19 September 2014

Published: 2 October 2014

\section{References}

1. Campanacci M, Baldini N, Boriani S, Sudanese A: Giant-cell tumor of bone. J Bone Joint Surg Am 1987, 69:106-114.

2. Yasko AW: Giant cell tumor of bone. Curr Oncol Rep 2002, 4:520-526.

3. Domovitov SV, Healey JH: Primary malignant giant-cell tumor of bone has high survival rate. Ann Surg Oncol 2010, 17:694-701.

4. Mendenhall WM, Zlotecki RA, Scarborough MT, Gibbs CP, Mendenhall NP: Giant cell tumor of bone. Am J Clin Oncol 2006, 29:96-99.
5. Raskin KA, Schwab JH, Mankin HJ, Springfield DS, Hornicek FJ: Giant cell tumor of bone. J Am Acad Orthop Surg 2013, 21:118-126.

6. Campanacci M, Capanna R, Fabbri N, Bettelli G: Curettage of giant cell tumor of bone. Reconstruction with subchondral grafts and cement. Chir Organi Mov 1990, 75:212-213.

7. Balke M, Schremper L, Gebert C, Ahrens H, Streitbuerger A, Koehler G, Hardes J, Gosheger G: Giant cell tumor of bone: treatment and outcome of 214 cases. J Cancer Res Clin Oncol 2008, 134:969-978.

8. Kivioja AH, Blomqvist C, Hietaniemi K, Trovik C, Walloe A, Bauer HC, Jorgensen PH, Bergh P, Folleras G: Cement is recommended in intralesional surgery of giant cell tumors: a Scandinavian Sarcoma Group study of 294 patients followed for a median time of 5 years. Acta Orthop 2008, 79:86-93.

9. Klenke FM, Wenger DE, Inwards CY, Rose PS, Sim FH: Giant cell tumor of bone: risk factors for recurrence. Clin Orthop Relat Res 2011, 469:591-599.

10. Blackley HR, Wunder JS, Davis AM, White LM, Kandel R, Bell RS: Treatment of giant-cell tumors of long bones with curettage and bone-grafting. J Bone Joint Surg Am 1999, 81:811-820.

11. Turcotte RE, Wunder JS, Isler MH, Bell RS, Schachar N, Masri BA, Moreau G, Davis AM: Giant cell tumor of long bone: a Canadian Sarcoma Group study. Clin Orthop Relat Res 2002, 397:248-258.

12. Niu X, Zhang Q, Hao L, Ding Y, Li Y, Xu H, Liu W: Giant cell tumor of the extremity: retrospective analysis of 621 Chinese patients from one institution. J Bone Joint Surg Am 2012, 94:461-467.

13. Becker WT, Dohle J, Bernd L, Braun A, Cserhati M, Enderle A, Hovy L, Matejovsky Z, Szendroi M, Trieb K, Tunn PU: Local recurrence of giant cell tumor of bone after intralesional treatment with and without adjuvant therapy. J Bone Joint Surg Am 2008, 90:1060-1067.

14. Errani C, Ruggieri P, Asenzio MA, Toscano A, Colangeli S, Rimondi E, Rossi G, Longhi A, Mercuri M: Giant cell tumor of the extremity: a review of 349 cases from a single institution. Cancer Treat Rev 2010, 36:1-7.

15. JaVe HL, Lichtenstein L, Portis RB: Giant cell tumor of bone. Its pathologic appearance, grading, supposed variants and treatment. Arch Pathol 1940, 30:993-1031.

16. Bieling $P$, Rehan $N$, Winkler $P$, Helmke $K$, Maas $R$, Fuchs $N$, Bielack $S$, Heise $U$, Jurgens $H$, Treuner J, Romanowski R, Exner U, Kotz R, Winkler K: Tumor size and prognosis in aggressively treated osteosarcoma. J Clin Oncol 1996, 14:848-858.

17. Enneking WF, Dunham W, Gebhardt MC, Malawar M, Pritchard DJ: A system for the functional evaluation of reconstructive procedures after surgical treatment of tumors of the musculoskeletal system. Clin Orthop Relat Res 1993, 286:241-246.

18. Wulling M, Engels $C$, Jesse N, Werner M, Delling G, Kaiser E: The nature of giant cell tumor of bone. J Cancer Res Clin Oncol 2001, 127:467-474.

19. Chakarun CJ, Forrester DM, Gottsegen CJ, Patel DB, White EA, Matcuk GR Jr: Giant cell tumor of bone: review, mimics, and new developments in treatment. Radiographics 2013, 33:197-211.

20. Goldring SR, Schiller AL, Mankin HJ, Dayer JM, Krane SM: Characterization of cells from human giant cell tumors of bone. Clin Orthop Relat Res 1986, 204:59-75.

21. Cowan RW, Singh G: Giant cell tumor of bone: a basic science perspective. Bone 2013, 52:238-246.

22. Scully SP, Mott MP, Temple HT, O'Keefe RJ, O'Donnell RJ, Mankin HJ: Late recurrence of giant-cell tumor of bone. A report of four cases. J Bone Joint Surg Am 1994, 76:1231-1233.

23. Trieb K, Bitzan P, Lang S, Dominkus M, Kotz R: Recurrence of curetted and bone-grafted giant-cell tumours with and without adjuvant phenol therapy. Eur J Surg Oncol 2001, 27:200-202.

24. Prosser GH, Baloch KG, Tillman RM, Carter SR, Grimer RJ: Does curettage without adjuvant therapy provide low recurrence rates in giant-cell tumors of bone. Clin Orthop Relat Res 2005, 435:211-218.

25. Wang HC, Chien SH, Lin GT: Management of grade III giant cell tumors of bones. J Surg Oncol 2005, 92:46-51.

26. Malek F, Krueger P, Hatmi ZN, Malayeri AA, Faezipour H, O'Donnell RJ: Local control of long bone giant cell tumour using curettage, burring and bone grafting without adjuvant therapy. Int Orthop 2006, 30:495-498.

27. Szendroi M, Kiss J, Antal I: Surgical treatment and prognostic factors in giant-cell tumor of bone. Acta Chir Orthop Traumatol Cech 2003, 70:142-150. 
28. Krishnan EC, Nelson C, Neff JR: Thermodynamic considerations of acrylic cement implant at the site of giant cell tumors of the bone. Med Phys 1986, 13:233-239.

29. Nelson DA, Barker ME, Hamlin BH: Thermal effects of acrylic cementation at bone tumour sites. Int J Hyperthermia 1997, 13:287-306.

30. Sakayama K, Sugawara Y, Kidani T, Miyawaki J, Fujibuchi T, Kamei S, Aizawa $J$, Yamamoto H: Diagnostic and therapeutic problems of giant cell tumor in the proximal femur. Arch Orthop Trauma Surg 2007, 127:867-872.

doi:10.1186/1471-2474-15-330

Cite this article as: Gao et al:: Local control of giant cell tumors of the long bone after aggressive curettage with and without bone cement. BMC Musculoskeletal Disorders 2014 15:330.

\section{Submit your next manuscript to BioMed Central and take full advantage of:}

- Convenient online submission

- Thorough peer review

- No space constraints or color figure charges

- Immediate publication on acceptance

- Inclusion in PubMed, CAS, Scopus and Google Scholar

- Research which is freely available for redistribution 